\title{
Dependence of Endothelial Cell Growth on Substrate-Bound Fibronectin
}

\author{
A. Poot, T. Beugeling, ${ }^{*}$ A. Dekker, J. Spijkers, J. A. van Mourik, J. Feijen, \\ A. Bantjes \& W. G. van Aken \\ University of Twente, Enschede, The Netherlands
}

\begin{abstract}
A better understanding of the mechanism of adhesion, spreading and proliferation of human endothelial cells (HEC) on polymeric surfaces may lead to the development of vascular prostheses which allow the formation of an endothelial lining on the luminal surface. In the present investigation the interaction of HEC with polyethylene precoated with monoclonal antibodies directed against HEC membrane antigens and against extracellular matrix compounds was studied. $\mathrm{F}\left(\mathrm{ab}^{\prime}\right)_{2}$ fragments of a monoclonal antibody, directed against an endothelial cell membrane antigen, and $\mathrm{F}\left(\mathrm{ab}^{\prime}\right)_{2}$ fragments of a monoclonal antibody, directed against cellular fibronectin, were also included in this study. Preadsorption of these antibodies and $F\left(a b^{\prime}\right)_{2}$ fragments, including mixtures of antibodies and mixtures of $F\left(a^{\prime}\right)_{2}$ fragments, resulted in cell adhesion and spreading as well as moderate cell proliferation (or no proliferation) for several days. However, a good proliferation of HEC was only observed on polyethylene precoated with fibronectin or CLB-HEC-FN-140 (directed against fibronectin). These results strongly suggest that fibronectin, bound to a solid substrate, provides a biochemical signal necessary for the proliferation of HEC. The initial proliferation of $\mathrm{HEC}$ on other preadsorbed antibodies or $\mathrm{F}\left(\mathrm{ab}^{\prime}\right)_{2}$ fragments may be explained by the fact that suspended HEC, used for cell seeding, still possess cell membrane-bound fibronectin.
\end{abstract}

\section{INTRODUCTION}

A better understanding of the mechanisms of adhesion, spreading and proliferation of human endothelial cells (HEC) on polymeric surfaces may lead to the development of vascular prostheses which allow the formation of an endothelial lining on the luminal surface. Earlier results from in-vitro experiments, carried out by Van Wachem et al., ${ }^{1}$ suggested that the ability to deposit cellular fibronectin on a polymer surface is a prerequisite for the spreading and proliferation of HEC. Evidence has been presented that cellular fibronectin deposition is accompanied by desorption of proteins adsorbed from the serum-containing culture medium to the polymer surface. ${ }^{2}$

The displacement of surface-adsorbed proteins by cellular fibronectin will occur more easily from

* To whom correspondence should be addressed. relatively hydrophilic surfaces compared to hydrophobic surfaces, because proteins are more strongly adsorbed to the latter surfaces. ${ }^{3,4}$ Most probably as a result of this phenomenon HEC do not adhere, spread and proliferate on hydrophobic polymers like polyethylene ${ }^{5}$ and polytetrafluoroethylene (Teflon) $^{6}$ whereas they are able to do so on moderately wettable polymers such as tissue culture polystyrene. ${ }^{78}$ However, hydrophobic polymers to which (plasma) fibronectin has been preadsorbed give rise to adhesion, spreading and proliferation of HEC. ${ }^{8}$

It has been reported that adhesion and spreading of baby hamster kidney (BHK) cells can be achieved by a substratum-adsorbed antibody which is directed against BHK cell membranes.. ${ }^{9}$ In the present investigation the interaction of $\mathrm{HEC}$ with polyethylene precoated with monoclonal antibodies directed against HEC membrane antigens and against extracellular matrix compounds was 
studied. In addition, $F\left(a b^{\prime}\right)_{2}$ fragments of a monoclonal antibody, directed against an endothelial cell membrane antigen, idnd $F\left(a b^{\prime}\right)_{2}$ fragments of a monoclonal antibody, directed against cellular fibronectin, were included in this study. The results with respect to adhesion, spreading and proliferation of $\mathrm{HEC}$ on these surfaces were compared with the results of experiments in which polyethylene had been precoated with purified human plasma fibronectin.

\section{MATERIALS AND METIIODS}

\section{Fibronectin}

Partially purified human fibronectin (Central Laboratory of the Netherlands Red Cross Blood Iransfusion Service (CLB) Amsterdam, The Netherlands) in PBS (pH 7.4) was purified with the aid of a gelatin-Sepharose $4 \mathrm{~B}$ column and filtered through a $0 \cdot 22 \mu \mathrm{m}$ Millipore filter. ${ }^{5}$

\section{Monoclonal antibodies and $F\left(\mathbf{a b}^{\prime}\right)_{2}$ fragments}

All monoclonal antibodies (see Table 1) were prepared and characterized at the CLB. ${ }^{5}$ Purified anti-erythrocyte antibody (negative control) dissolved in PBS was used as received from the CLB (CLB-ery/1). The other antibodies were isolated and purified from mouse ascites fluid by chromatography on protein-A-Sepharose (Pharmacia). ${ }^{5} \mathrm{~A}$ protein-A-Sepharose column was also used for the isolation of mouse $\operatorname{IgG}$ (negative control) from mouse serum (CLB).

$\mathrm{F}\left(\mathrm{ab}^{\prime}\right)_{2}$ and $\mathrm{Fc}$ fragments were prepared by means of digestion of purified CLB-HEC-19 and CLBHEC-FN-140 antibodies with Sepharoseimmobilized pepsin (Pierce, Rockford, IL.). ${ }^{5}$ $\left.\mathrm{F}(\mathrm{ab})_{2}\right)_{2}$ and $\mathrm{Fc}$ fragments were separated by chromatography on protein-A-Sepharose.

Table 1. Monoclonal antibodies

\begin{tabular}{ll}
\multicolumn{1}{c}{ Code } & \multicolumn{1}{c}{ Directed against } \\
\hline CLB-HEC-19 & Membrane glycoprotein of HEC \\
CLB-HEC-347 & Membrane glycoprotein of HEC \\
CLB-10G11 & Glycoprotein Ia-IIa \\
CLB-HEC-65 & Glycoprotein Ila (CD 31) \\
CLB-C17 & Glycoprotein IIb-IIIa \\
CLB-Rag 38 & von Willebrand factor \\
CLB-HEC-FN-140 & Human fibronectin \\
Anti-erythrocyte & Erythrocytes; glycophorin A \\
\hline
\end{tabular}

Coating of polyethylene with fibronectin, antibodies and $\mathrm{F}\left(\mathrm{ab}^{\prime}\right)_{2}$ fragments

Low density polyethylene sheets (TALAS, Ommen, The Netherlands) were ultrasonically cleaned in a $1 \%(\mathrm{v} / \mathrm{v})$ detergent solution (RBS 25, Hicol, OudBeijerland, The Netherlands) for $30 \mathrm{~min}$ and ex. tensively rinsed with distilled water and ethanol (Merck). The sheets were mounted in a test device as described earlier, and exposed to protein solutions of $0.05 \mathrm{mg} / \mathrm{mL}$ at $4^{\circ} \mathrm{C}$ for $15-17$ hours. ${ }^{7,30}$

For proliferation experiments the test devices were sterilized by means of ethylene oxide before protein coating. The protein solutions were filtered through a $0.22 \mu \mathrm{m}$, low protein-binding, Millipore filter. After protein adsorption the surfaces were rinsed three times with PBS.

\section{Cell adhesion and proliferation}

HEC were isolated from human umbilical cord veins according to the isolation method of Willems et al. ${ }^{11}$ Cells were routinely cultured in tissue culture polystyrene flasks (Costar Europe) precoaled with partially purified fibronectin. ${ }^{12}$

Culture medium consisted of a 1:1 mixture of medium 199 and RPMII 1640 (both from Gibco), containing $20 \%$ pooled human serum, with $2 \mathrm{~mm}$ L-glutamine (Merck), $100 \mathrm{IU} / \mathrm{mL}$ penicillin $(\mathrm{IU}$, international units), $100 \mu \mathrm{g} / \mathrm{mL}$ streptomycin (both from Flow Laboratories) and $4 \mu \mathrm{g} / \mathrm{mL}$ fungizone (Gibco).

Cells were harvested by means of trypsin $(0.05 \%)$, after which trypsin was inactivated by addition of serum-containing culture medium. Subsequently, the isolated cells were washed three times with culture medium lacking serum and resuspended in serum-free medium.

HEC were seeded into the wells of the test device mentioned above. The cell suspensions used for seeding contained 125000 and 31000 cells $/ \mathrm{cm}^{2}$ for adhesion and proliferation experiments respectively. The surface areas for cell adhcsion and proliferation experiments were 0.8 and $1.3 \mathrm{~cm}^{2}$. Adhesion and proliferation experiments were carried out at $37^{\circ} \mathrm{C}$. Cell adhesion was measured after $2 \mathrm{~h}$ and cell proliferation was determined after 2,6 and 9 days. For the proliferation experiments the cells were allowed to adhere for $2 \mathrm{~h}$, after which the serum-free culture medium was replaced by serumcontaining medium. This culture medium was refreshed three times per week. The number of adherent cells was determined either by counting 
the nuclei of the cells with a flow cytometer (Technicon, Avelingen, The Netherlands) or by measuring the amount of DNA by means of Hoechst dye $33258 .{ }^{13,14}$

\section{RESULTS AND DISCUSSION}

Results of in-vitro experiments carricd out by Van Wachem et al. suggested that human endothelial cells (HEC) have to deposit fibronectin onto a polymer surface in order to adhere, spread and proliferate. ${ }^{1}$ It has been made plausible in the introduction of this paper that these processes may occur if the substratum is a (moderately) waterwettable polymer but that they do not occur in the case of a hydrophobic polymer unless the surface of this polymer has been precoated with fibronectin.

Another method to bind cells to a solid surface was reported by Grinnell and Hays and involves the use of substratum-bound antibodies, which are directed against the plasma membrane of cells. ${ }^{9}$ In the present investigation the adhesion, spreading and proliferation of HEC on polyethylene, precoated with monoclonal antibodies directed against cell membrane antigens and against extracellular matrix proteins, were examined, In addition, $\mathrm{F}\left(\mathrm{a} \mathrm{b}^{\prime}\right)_{2}$ fragments of two of these monoclonal antibodies were included in this study.

Based on the results of experiments in which the adhesion of HEC was measured as a function of the fibronectin concentration and of the concentration of the antibodies in the coating solutions, the concentrations of the coating solutions were taken

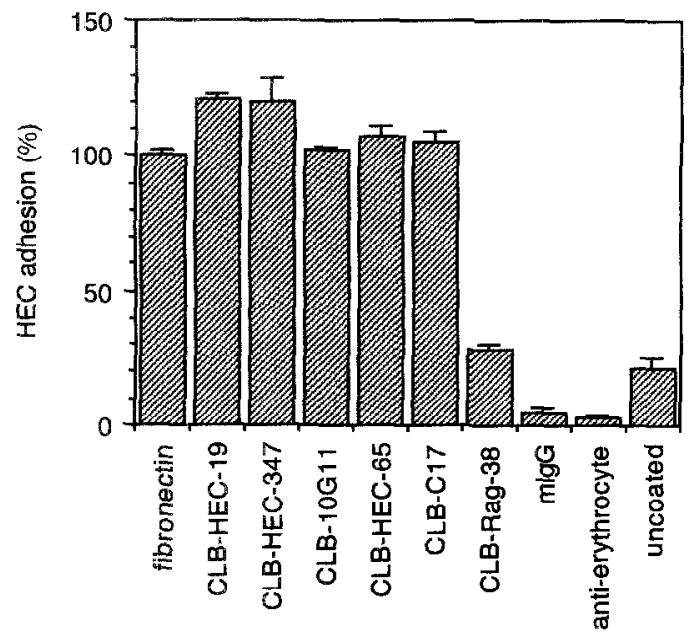

Fig. 1. Adhesion of endothelial cells on to uncoated polyethylene and polyethylene coated with various antibodies after $2 \mathrm{~h}$ of incubation. Cell adhesion is expressed as a percentage of the number of cells adhered to polyethylene coated with fibronectin. All values are means of four determinations ( \pm s.d.) as $0.05 \mathrm{mg} / \mathrm{mL}$. It was found that cell adhesion already reached a plateau value at a protein concentration of about $0.025 \mathrm{mg} / \mathrm{mL}$.

Figure 1 shows the results with respect to the adhesion of HEC to uncoated polyethylene and polyethylene precoated with the various anti-HFC, antibodies. The results of HEC adhesion to polyethylene precoated with fibronectin, mouse IgG and anti-erythrocyte are also shown in this figure. The largest numbers of adherent HEC were observed on surfaces coated with the monoclonal antibodies CLB-HEC-19 and CLB-HEC-347. The adhesion of HEC on polyethylene precoated with the antibodies CLB-10G11, CLB-HEC-65 and CLB-C17 was similar to the adhesion on the fibronectin-coated surface. Cell spreading on the polyethylene surfaces coated with CLB-HEC-19, CLB-HEC-347, CLB10G11, CLB-HEC-65 and CLB-C17 was not quite as good as on the reference surface.

Significantly less cell adhesion was observed on polyethylene coated with CI.B-Rag 38 (directed against the von Willebrand factor) and on uncoated polyethylene. HEC were not well spread on these surfaces. As expected, HEC hardly adhered to polyethylene coated with mouse $\operatorname{IgG}$ or antierythrocyte.

Polyethylene precoated with CLB-HEC-FN-140 (directed against fibronectin) was not included in the experiments from which the results are presented in Fig. 1, but the results of HEC adhesion ( 0 days $=2 \mathrm{~h}$ ) and proliferation ( 6 days) on this surface are shown in Fig. 2, together with the results of HEC adhesion and proliferation on polyethylene precoated with the antibodies CLB-HEC-19, CLBRag-38 and mouse IgG. HEC adhesion and proliferation on uncoated polyethylene and polyethylene coated with fibronectin were also determined.

The numbers of HEC adhered after $2 \mathrm{~h}$ to polyethylene coatcd with CLB-Rag-38 (Figs 1 and 2) and CLB-HEC-FN-140 (Fig. 2) were rather low compared with the number of cells adhered to the fibronectin-coated surface. HEC showed very good adhesion to the CLB-HEC-19 surface (Fig. 1) but HEC did not proliferate on this surface. Therefore HEC adhesion and proliferation were also determined on polyethylene precoated with mixtures of antibodies. The results of these experiments are also presented in Fig. 2.

HEC did not proliferate on polyethylene coated with mixtures of antibodies in which relatively high concentrations of CLB-HEC-19 were present. ${ }^{5}$ For this reason the concentration of CLB-HEC- 19 in the 


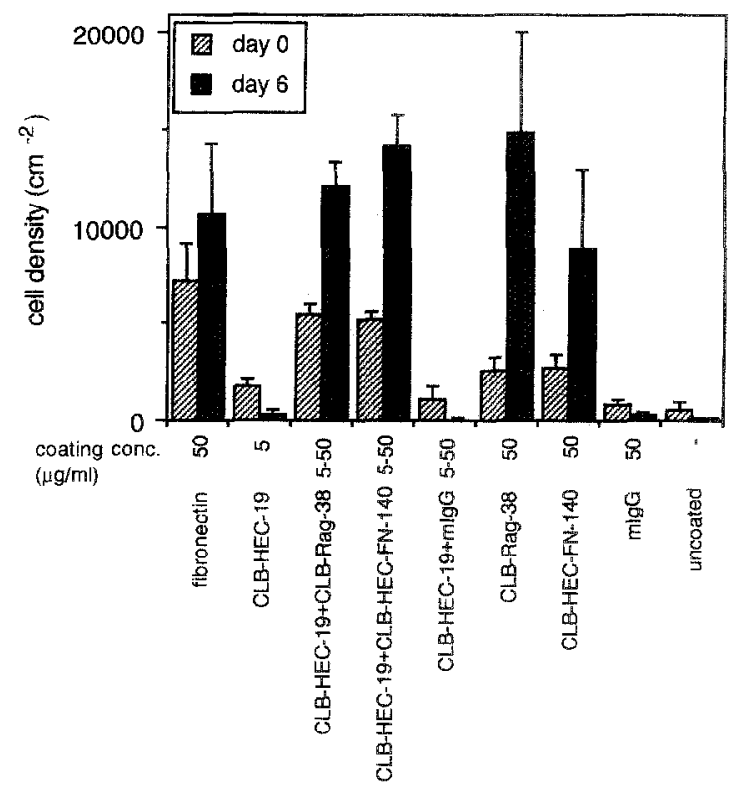

Fig. 2. Proliferation of endothelial cells after 0 days $(-2 h)$ and 6 days on uncoated polyethylene, on fibronectin-coated polyethylene, on polyethylene coated with antibodies and on polyethylene coated with mixtures of antibodies. Values are means of three determinations ( \pm s.d.).

coating solutions was kept rather low $(5 \mu \mathrm{g} / \mathrm{mL})$. Proliferation of HEC determined after 6 days was found to occur on polyethylene coated with fibronectin, CLB-HEC-FN-140, CLB-Rag-38, mixtures of CLB-HEC-19 and CLB-Rag-38, and mixtures of CLB-HEC-19 and CLB-HEC-FN-140 (Fig. 2).

It must be mentioned, however, that cell spreading on polyethylene precoated with CLB-Rag-38 (directed against the von Willebrand factor) or the mixture of antibodies in which CLB-Rag-38 was present was not very good. In these cases the edges of many cells had been detached from the material surface. In agreement with earlier results from our laboratory HEC did not proliferate on uncoated polyethylene and polyethylene coated with mouse IgG. ${ }^{5,8} \mathrm{HEC}$ also did not proliferate on polyethylene treated with a solution containing a low concentration of CLB-HEC-19 $(5 \mu \mathrm{g} / \mathrm{mL})$.

Earlier experiments showed that proliferation of HEC did not occur or hardly occurred on polycthylenc precoated with the antibodies CLB-HEC$19(50 \mu \mathrm{g} / \mathrm{mL})$, CLB-HEC-347, CLB-10G11, CLBHEC-65 and CLB-C17.15 These antibody-coated surfaces gave rise to good cell adhesion (Fig. 1). ${ }^{15}$ Evidently, attachment and spreading of HEC on a solid surface does not automatically lead to cell proliferation.

Intact monoclonal antibodies, adsorbed to a solid surface, may interact with blood platelets via their $\mathrm{Fc}$ part. ${ }^{16} \mathrm{By}$ precoating of vascular grafts with $F\left(a b^{\prime}\right)_{2}$ fragments of monoclonal antibodies

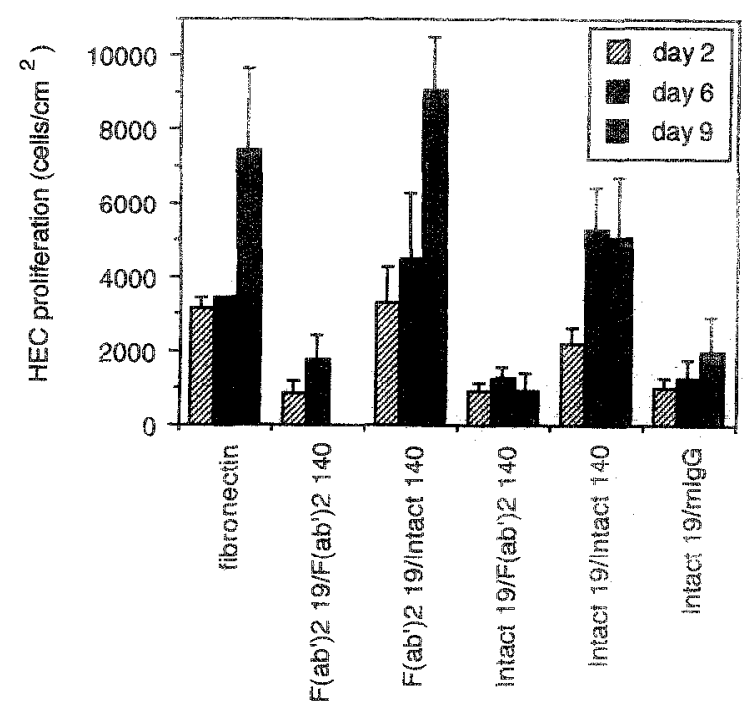

Fig. 3. Proliferation of endothelial cells after 2,6 and 9 days on fibronectin-coated polyethylene, on polyethylene coated with mixtures of antibodies, on polyethylene coated with mixtures of antibodies and $\mathrm{F}\left(\mathrm{a} \mathrm{b}^{\prime}\right)_{2}$ fragments, and on polyethylene coated with a mixture of $\mathrm{F}\left(a b^{\prime}\right)_{2}$ fragments. Values are means of three determinations ( \pm s.d.).

instcad of intact antibodics, platelct adhosion may thus be prevented. For this reason, polyethylene coated with $\mathrm{F}\left(\mathrm{ab}^{\prime}\right)_{2}$ fragments was also included in the proliferation studies.

In Figure 3 the results are shown with respect to the proliferation of HEC, determined after 2, 6 and 9 days, on polyethylene precoated with fibronectin and on polyethylene precoated with mixtures consisting of intact antibodies, mixtures of antibodies and $F\left(a b^{\prime}\right)_{2}$ fragments, and a mixture of $\mathrm{F}\left(a b^{\prime}\right)_{2}$ fragments.

HEC proliferated well on polyethylene coated with a mixture of intact CLB-HEC-FN-140 and $\mathrm{F}\left(\mathrm{ab}^{\prime}\right)_{2}$ fragments from CLB-HEC-19. HEC showed al moderate to good proliferation on polyethylene coated with a mixture of the intact monoclonal antibodies CLB-HEC-19 and CLBHEC-FN-140. This result is in agreement with the results presented in Fig. 2. A good cell spreading was observed in experiments in which HEC proliferated well.

The results obtained from our proliferation experiments carried out thus far suggest that a good proliferation of IIEC only takes place on polyethylene that has been precoated with fibronectin or on polyethylene that can indirectly bind (cellular) fibronectin via CLB-HEC-FN-140.

Figure 3 shows that HEC hardly proliferated when $F\left(a b^{\prime}\right)_{2}$ fragments of CLB-HEC-FN-140 instead of intact antibody molecules had been adsorbed to polyethylene. This may be explained by a reduced capacity of the adsorbed $F\left(a b^{\prime}\right)$, frag- 
ments to bind fibronectin $( \pm 40 \%$ compared to the capacity of the intact antibody) and is probably caused by the preparation procedure to obtain $\mathrm{F}\left(\mathrm{a} b^{\prime}\right)_{2}$ fragments. Hardly any proliferation of HEC was observed on polyethylene precoated with a mixture of the antibodies CLB-HEC-19 and mouse IgG. This is in agreement with the results mentioned before.

A dependence of HEC proliferation on fibronectin, directly or indirectly bound to a substratum, explains why HEC do not proliferate on polyethylene precoated with antibodies or $\mathrm{F}\left(\mathrm{ab}^{\prime}\right)_{2}$ fragments that do not bind fibronectin. The hydrophobic polyethylene strongly adsorbs proteins; therefore, these antibodies or $\mathrm{F}\left(\mathrm{ab}^{\prime}\right)_{2}$ fragments are not easily displaced from the polyethylene surface by cellular fibronectin.

If substratum-bound fibronectin is really a prerequisite for the proliferation of HEC, it is conceivable that part of the bound fibroncetin moleculc provides a biochemical signal which initiates a series of events in the endothelial cell leading to DNA replication. Probably HEC are also triggered by this biochemical signal to synthesize and secrete cellular fibronectin. More experiments have to be carried out, however, in order to come to conclusions about such a role of fibronectin.

\section{ACKNOWLEDGEMENT}

Financial support by The Netherlands Heart Foundation (grant 88.078) is gratefully acknowledged.

\section{REFERENCES}

1. Van Wachem, P. B., Beugeling, T., Mallens, B. W. L., Dekker, A., Feijen, J., Bantjes, A. \& Van Aken, W. G., Dcposition of endothelial fibronectin on polymeric surfaces. Biomaterials, 9 (1988) 121-3.

2. Dekker, A., Beugeling, T., Wind, H., Poot, A., Bantjes, A., Feijen, J. \& Van Aken, W. G,, Deposition of cellular fibronectin and desorption of human serum albumin during adhesion and spreading of human endothelial cells on polymers. I. Mater. Sci., Materials in Medicine, 2 (1991) 227-33.

3. Feijen, J., Beugeling, T., Bantjes, A. \& Smit Sibinga, C. Th., Biomaterials and interfacial phenomena. In Advances in Cardiovascular Physics, cd D. N. Ghista, Vol. 3. KargerBasel, 1979, p. 100.

4. Brash, J. L., Mechanism of adsorption of proteins to solid surfaces and its relationship to blood compatibility. In Biocompatible Polymers, ed. M. Szycher, Technomic, Lancaster, Pennsylvania, USA, 1983, p. 35.

5. Dekker, A., Poot, A. A., Van Mourik, J. A., Workel, M. P. A., Beugeling, T., Bantjes, A., Feijen, J. \& Van Aken, W. G., Improved adhesion and proliferation of human endothelial cells on polyethylene precoated with monoclonal antibodies directed against cell membrane antigens and extracellular matrix proteins. Thromb. Haemost., 66 (1991) 715-24.

6. Dekker, A., Reitsma, K., Beugeling, T., Bantjes, A., Feijen, J. \& Van Aken, W. G., Adhesion of endothelial cells and adsorption of serum proteins on gas plasmatreated polytetrafluoroethylene. Biomaterials, 12 (1991) $130-8$.

7. Van Wachem, P. B., Beugeling, T., Feijen, J., Bantjes, A., Detmers, J. P. \& Van Aken, W. G., Interaction of cultured human endothelial cells with polymeric surfaces of different wettabilities. Biomaterials, 6 (1985) $403-8$.

8. Van Wachem, P. B., Vreriks, C. M., Beugeling, T., Feijen, J., Bantjes, A., Detmers, J.P. \& Van Aken, W. G., The influence of protein adsorption on interactions of cultured human endothelial cells with polymers. $J$. Biomed. Mater. Res., 21 (1987) 701-8.

9. Grinnell, F. \& Hays, D. G., Induction of cell spreading by substratum-adsorbed ligands directed against the cell surface. Exp. Cell Res., 116 (1978) 275-84.

10. Poot, A., Beugeling, T., Van Aken, W. G. \& Bantjes, A., Detection of surface-adsorbed (lipo)proteins by means of a two-step enzyme-immunoassay: a study on the Vroman effect. J. Biomed. Mater. Res., 24 (1990) 1021-36.

11. Willems, Ch., Astaldi, G. C. B., De Groot, Ph. D., Jansen, M. C., Gonsalves, M. D., Zeijlemaker, W. P., Van Mourik, J. A \& Van Aken, W. G., Media conditioned by cultured vascular endothelial cells inhibit the growth of vascular smooth muscle cells. Exp. Cell Res., 139 (1982) 191

12. Van Wachem, P. B., Reinders, J.H., Van BuulWortelboer, M. F., De Groot, Ph. D., Van Aken, W. G. \& Van Mourik, J.A., Von Willebrand factor in cultured human vascular endothelial cells from adult and umbilical cord arteries and veins. Thromb. Haemost., 56 (1986) 189.

13. West, D. C., Sattar, A. \& Kumar, S., A simplified in situ solubilization procedure for the determination of DNA and cell number in tissue cultured mammalian cells. Anal. Biochem., 147 (1985) 289.

14. Mates, G., Daniel, M. \& Walker, C., Factors affecting the reproducibility of a spectrofluorometric assay for the enumeration of human venous endothelium in culture. Cell Biol. Int. Rep., 10 (1986) 641.

15. Dekker, A., Adhesion and proliferation of human endo thelial cells on polymeric surfaces. Optimization studies. $\mathrm{PhD}$ thesis, University of Twente, The Netherlands, 1990.

16. Poot, A., Dekker, A., Van Mourik, J. A., Spijkers, J., Machielsen, A., Beugeling, T., Bantjes, A., Feijen, J. \& Van Aken, W. G., Promotion of endothelial coverage and decrease of platelet reactivity of artificial surfaces using monoclonal antibodies directed against endothelial cells. In Proceedings of IVth International Symposium on Biology of Vascular Cells, Paris, 28-31 August 1990, p. 60. 